\title{
Microbial communities associated with uranium in-situ recovery mining process are related to acid mine drainage assemblages
}

\author{
Thomas Coral ${ }^{\mathrm{a}}$, Michaël Descostes ${ }^{\mathrm{b}}$, Hélène De Boissezon ${ }^{\mathrm{b}}$, Rizlan Bernier-Latmani ${ }^{\mathrm{c}}$, \\ Luiz Felippe de Alencastro ${ }^{a}$, Pierre Rossi ${ }^{\mathrm{a}, *}$ \\ a Central Environmental Laboratory, School of Architecture, Civil and Environmental Engineering, Ecole Polytechnique Fédérale de Lausanne, Station 2, 1015 Lausanne, Switzerland \\ b AREVA Mines, RED Dpt., Tour AREVA, 1, place Jean Millier, 92084 Paris, La Défense, France \\ ${ }^{\mathrm{c}}$ Environmental Microbiology Laboratory, School of Architecture, Civil and Environmental Engineering, Ecole Polytechnique Fédérale de Lausanne, Station 6, 1015 Lausanne, Switzerland
}

\section{H I G H L I G H T S}

- Redox gradient shaped community structures within the native aquifer zones.

- Acid injection favors acidophilic chemolithoautotrophic Bacteria and Archaea.

- This acidophilic community shared strong similarities with AMD-related communities.

- Up- and down-stream affected zones showed signs of resilience to ISR fluids.

- Assessing community structures is necessary for the setup of remediation strategies.

\section{A R T I C L E I N F O}

\section{Article history:}

Received 13 November 2017

Received in revised form 26 January 2018

Accepted 30 January 2018

Available online xxxx

Editor: F.M. Tack

\section{Keywords:}

Uranium

In-situ recovery

Kazakhstan

Acid mine drainage

Acidophilic bacteria

Natural attenuation

Next-generation sequencing

Multivariate statistics
G R A P H I C A L A B S T R A C T
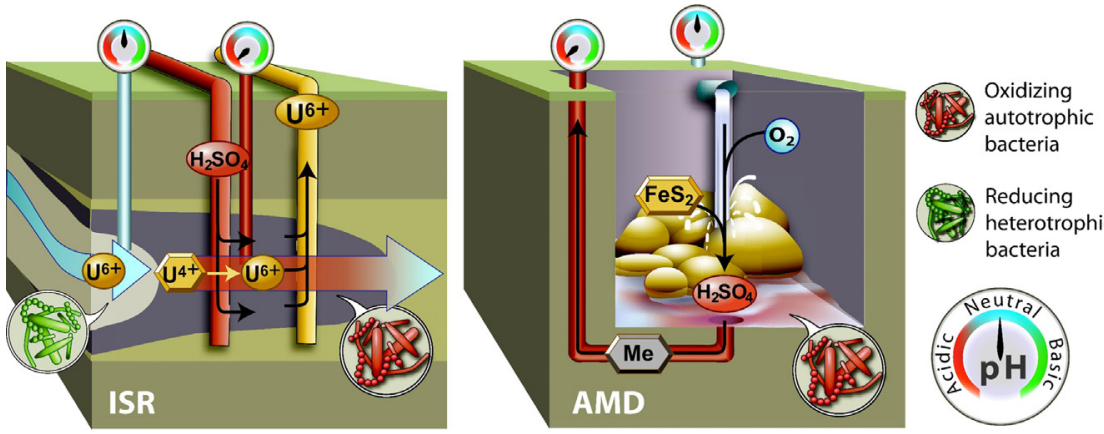

\begin{abstract}
A B S T R A C T
A large fraction (47\%) of the world's uranium is mined by a technique called "In Situ Recovery" (ISR). This mining technique involves the injection of a leaching fluid (acidic or alkaline) into a uranium-bearing aquifer and the pumping of the resulting solution through cation exchange columns for the recovery of dissolved uranium. The present study reports the in-depth alterations brought to autochthonous microbial communities during acidic ISR activities. Water samples were collected from a uranium roll-front deposit that is part of an ISR mine in operation (Tortkuduk, Kazakhstan). Water samples were obtained at a depth of $c a 500 \mathrm{~m}$ below ground level from several zones of the Uyuk aquifer following the natural redox zonation inherited from the roll front deposit, including the native mineralized orebody and both upstream and downstream adjacent locations. Samples were collected equally from both the entrance and the exit of the uranium concentration plant. Next-generation sequencing data showed that the redox gradient shaped the community structures, within the anaerobic, reduced, and oligotrophic habitats of the native aquifer zones. Acid injection induced drastic changes in the structures of these communities, with a large decrease in both cell numbers and diversity. Communities present in the acidified ( $\mathrm{pH}$ values $<2$ ) mining areas exhibited similarities to those present in acid mine drainage, with the dominance of Sulfobacillus sp., Leptospirillum sp. and Acidithiobacillus sp., as well as the archaean Ferroplasma sp. Communities located up- and downstream of the mineralized zone under ISR and affected by acidic fluids were blended with additional facultative anaerobic and acidophilic microorganisms. These mixed biomes may
\end{abstract}

\footnotetext{
* Corresponding author at: EPFL ENAC IIE GR-CEL, CH A1 374 (Bat CH), Station 6, 1015 Lausanne, Switzerland.

E-mail address: pierre.rossi@epfl.ch (P. Rossi).
} 
be suitable communities for the natural attenuation of ISR mining-affected subsurface through the reduction of metals and sulfate. Assessing the effect of acidification on the microbial community is critical to evaluating the potential for natural attenuation or active bioremediation strategies.

(C) 2018 Elsevier B.V. All rights reserved.

\section{Introduction}

In Situ Recovery (ISR) is a mining strategy that accounts for almost half of the world's uranium production worldwide (World Nuclear Association, 2016). This alternative to conventional mining utilizes a series of injection and extraction wells to pump a leachate into a mineralized aquifer, resulting in ore dissolution, and to pump back the uranium bearing solution to the surface for further processing (Benes et al., 2001). The dissolved compound of interest (here uranium) is typically removed from solution using ion exchange columns. Further refining purifies the material into a commercial product (Morrell, 2013). ISR is considered advantageous over traditional mining techniques involving mechanical crushing and grinding because it requires lower operational costs and can be applied to relatively low-grade ores (Benes et al., 2001; Rawlings, 2002). ISR is deployed over a limited surface area and mill tailing or waste rock deposit are absent. Mining for uranium with ISR occurs in locations where the ore is deposited within a sedimentary rock or sediment layer with a relatively high hydraulic conductivity (e.g., sandstone) that lies between two relatively impermeable layers, and preferably below the water table (Benes et al., 2001). These deposits are formed when oxidized and mobile uranium precipitates within organic carbon-rich host unit, meeting reducing conditions. Alkaline ISR is used when the composition of the deposit contains typically more than $2 \%$ calcite, which corresponds to the vast majority of the cases. Else acid, a relatively dilute solution containing sulfuric acid, is used. Injection of sulfuric acid into the subsurface drastically alters the groundwater geochemistry (Saunders et al., 2016). The leachate, commonly at $\mathrm{pH}$ values $<2$, dissolves minerals and mobilizes metals, thereby increasing the concentrations of dissolved solids in groundwater. The mobile metals have the potential to travel long distances and contaminate adjacent aquifer sections (Taylor et al., 2004; Belitz et al., 2015; Alrakabi et al., 2012). In addition to being radioactive and forming decay products, such as ${ }^{226}$ radium, uranium itself exhibits toxicity. Recent examples of aquifer contamination demonstrate the urgent need to develop technologies for the removal of uranium released by mining activities (Watson et al., 2013; Williams et al., 2013; Romero-González et al., 2016).

The origin and the nature of the microbial communities associated with extremely acidic environments have been described in detail a few years ago (Johnson, 2012). These environments typically develop through the abiotic and microbial oxidation of metal sulfides in the presence of oxygen, producing sulfuric acid (Baker and Banfield, 2003; Kimura et al., 2011). Acid-mine drainage (AMD) is the highly acidic, metal-laden water produced from uncontrolled former mines (Johnson, 2012). Prokaryotes that are metabolically active in AMD have been reviewed in detail elsewhere (Johnson and Hallberg, 2003; Kimura et al., 2011; Dopson and Johnson, 2012; Volant et al., 2014). The main phyla present in these acidic habitats are Proteobacteria, Nitrospira, Actinobacteria, Firmicutes, and Acidobacteria, with the occasional presence of representatives of the phyla Bacteroidetes and TM7 (candidate phylum). Recent work on the ecology of prokaryotes involved in the oxidation of reduced sulfur compounds (such as Sulfobacillus sp. and Acidithiobacillus sp.) and metals (Leptospirillum sp., Thiobacillus sp., Ferroplasma sp.) in acidic environments has benefited from next-generation sequencing efforts and has shed light on community structure and biogeochemical cycling in these environments (Chen et al., 2016; Méndez-García et al., 2015; Kuang et al., 2013). Further research highlighted the ecological functioning of AMD-related communities, including aspects related to carbon cycle and molecular nitrogen fixation (Huang et al., 2016).
For ISR, acidification of the subsurface with sulfuric acid is hypothesized to contribute to the establishment of a microbial community with similarities to AMD communities. For either natural attenuation or active bioremediation to be successful post-ISR, it is critical to understand the effect of acidification on the microbial communities within the impacted groundwater. Remediation of uranium contamination typically relies on the establishment of reducing conditions in the subsurface and natural or engineered processes resulting in a reduced zone would allow the aquifer section affected by ISR to return to its original state. For instance, stimulation of anaerobic subsurface bacteria with organic matter has the potential to neutralize the acid and either create mineral species capable of uranium reduction or to directly (enzymatically) precipitate uranium species (Wall and Krumholz, 2006; BernierLatmani et al., 2010; Williams et al., 2013; Newsome et al., 2015). Furthermore, metals could be immobilized as sulfides precipitates (Watson et al., 2013). The goals of this study are i) to assess comprehensively the impact of ISR fluids on the autochthonous microbial communities present within an aquifer undergoing mining activities and ii) to compare these communities to those found commonly in AMD habitats.

\section{Material and methods}

\subsection{Groundwater sampling}

More than $50 \%$ of the uranium production in Kazakhstan comes from the Chu-Sarysu artesian basin (Dahlkamp, 2009). This region is a geological depression located between the Karataou and Chu-Illi mountains (Yazhikov, 1996). Samples (Table 1) were obtained from various redox compartments of the Uyuk aquifer within the Tortkuduk deposit (Eastern Chu-Sarysu), in agreement with the roll front deposit geometry.

With the exception of the "IN" and "OUT" samples, groundwater samples were taken from a depth of ca. $500 \mathrm{~m}$ below ground level (bgl) using a submerged pump. Sampling was carried out after stabilization of the on-line parameters measured in-situ (temperature, $\mathrm{pH}$, redox, conductivity, dissolved oxygen) and the pumping out of a minimum of three well volumes. Samples were collected in 101 plastic vessels treated beforehand with $5 \%$ hydrochloric acid for $24 \mathrm{~h}$. Samples were kept in a cooled ice-box protected from light and processed within the next $4 \mathrm{~h}$

Table 1

List of samples collected from the Uyuk aquifer and the uranium collection factory. Both "upstream" and "downstream" are relative to the roll front area in which ISR is conducted.

\begin{tabular}{|c|c|c|}
\hline $\begin{array}{l}\text { Sample } \\
\text { names }\end{array}$ & Sample origins & Details \\
\hline UP & Uyuk aquifer & Upstream zone, native aquifer, pristine \\
\hline MIN & Uyuk aquifer & $\begin{array}{l}\text { Mineralized, roll-front uranium-rich, native aquifer, } \\
\text { pristine }\end{array}$ \\
\hline DWN & Uyuk aquifer & Downstream zone, native aquifer, pristine \\
\hline UP-acid & Uyuk aquifer & Upstream zone, affected by ISR fluids \\
\hline DWN1-acid & Uyuk aquifer & Downstream, affected by ISR fluids \\
\hline DWN2-acid & Uyuk aquifer & Downstream, affected by ISR fluids \\
\hline IN & $\begin{array}{l}\text { Concentration } \\
\text { factory }\end{array}$ & Inlet, before uranium concentration \\
\hline OUT & $\begin{array}{l}\text { Concentration } \\
\text { factory }\end{array}$ & $\begin{array}{l}\text { Outlet, after uranium concentration and before } \\
\text { re-injection into the aquifer }\end{array}$ \\
\hline
\end{tabular}




\subsection{Chemical analyses}

Water samples for chemical analysis was filtered through $0.22 \mathrm{um}$ filters (Millipore, USA) in 1-1 HDPE plastic containers. Samples for cations analysis were acidified with $0.05 \%$ ultra-pure nitric acid. Cations and anions were analyzed with IC (Ion Chromatography System ICS3000, Dionex). Metals were analyzed with ICP-OES (Multitype ICP Emission Spectrometer, ICPE-9000, Shimadzu). TOC and TIC were analyzed on a TOC-V Series (Shimadzu).

\subsection{DNA extraction}

Microbial cells were collected onto 0.2 um, 142 mm diameter, sterile PES filters using a stainless steel filter holder (all Millipore, USA). Each filter collected cells from 2 to 31 of aquifer sample and was then rinsed with 11 of sterile deionized water followed by 11 of sterile TE buffer. Filters were folded and inserted into sterile plastic bags (Whirl-pack, Nasco, USA) and frozen at $-20^{\circ} \mathrm{C}$ until DNA extraction. DNA extraction was carried out as mentioned in Tarnawski et al. (2016).

\subsection{Next-generation library preparation}

Library preparation was carried out as shown in Diaby et al. (2015). Briefly, PCR amplification of the 16S rRNA hypervariable regions V1-V3 was carried out using bacterial HPLC-purified bacterial primers 28f and 519rm (5'-GAGTTTGATCNTGGCTCAG-3' and 5'GTNTTACNGCGGCKGCTG-3' respectively) and archaeal primers $109 \mathrm{f}$ and $915 \mathrm{r}$ (5'-ACKGCTCAGTAACACGT-3' and 5'-GTGCTCCCCCGCCAATTCC respectively), with $0.1 \mathrm{ng} / \mu \mathrm{l}$ of template DNA (final concentration). Amplicons ca. $520 \mathrm{bp}$ were generated in $50 \mu \mathrm{l}$ reaction volumes containing $5 \mu \mathrm{l}$ of $10 \times$ PCR Buffer, $5 \mu \mathrm{l}$ of $25 \mathrm{mM} \mathrm{MgCl}_{2}, 9 \mu \mathrm{l}$ of Enhancer P, $3.6 \mu \mathrm{l}$ of dNTPs $(2.5 \mu \mathrm{M}$ each $), 1 \mu \mathrm{l}$ of each primer $(10 \mu \mathrm{M})$ and $0.5 \mu \mathrm{l}$ of PeqGold DNA polymerase (all PeqLab, Germany). PCR amplification conditions were as follows: $94^{\circ} \mathrm{C}$ for $5 \mathrm{~min}$, followed by 25 cycles of $94^{\circ} \mathrm{C}$ for $30 \mathrm{~s}$, $56{ }^{\circ} \mathrm{C}$ for $30 \mathrm{~s}, 72^{\circ} \mathrm{C}$ for $60 \mathrm{~s}$, and a final elongation step of $72{ }^{\circ} \mathrm{C}$ for 5 min. Amplicons purification was carried out with magnetic beads (AxyPrep Mag PCR Clean-Up, Axygen, USA). Amplicons were reduced in size using the enzymes provided in the Ion Xpress Plus Fragment Library Kit and were fused with both adaptors $A$ and the barcoded Pi (Ion Xpress Barcode Adapters) according to the manufacturer's instructions (Life Technologies). Size selection ( $\max 490 \mathrm{bp}$ ) was carried out on agarose gels ( $E$-Gel System, Life Technologies). Quantification of the fragments was carried out using a BioAnalyser 2100 and the High Sensitivity DNA chips (Agilent technologies).

\subsection{Semiconductor sequencing}

Next-generation sequencing was conducted on an Ion Torrent Personal Genome Machine as shown in Diaby et al., 2015. Emulsion PCR was carried out applying the Ion XPress Plus Template Kit (Life Technologies) as described by the manufacturer. Sequencing of the amplicons was carried out using the Ion Sequencing 400 kit (Life Technologies) on a 316 chip following the corresponding protocol. Pooled barcoded samples were loaded on the same chip.

\subsection{Sequence analysis}

Data were processed on Mothur (Schloss et al., 2009), including denoising with the Single Linkage Preclustering (SLP) method (Huse et al., 2010) and testing for absence of chimera using the UCHIME algorithm (Edgar et al., 2011) and the SILVA database (Quast et al., 2013). Hierarchical clustering was carried out using Esprit-Tree (Cai and Sun, 2011). The freeware R (R Development Core Team, 2009) was used subsequently for numerical ecology analysis and inference statistics, for the computation of Fishers's $\alpha$ index (a semi-parametric index independent from the size of the sampling) and Pielou's evenness. Multifactorial analysis (MFA) and correlation analysis were conducted on chemical and microbial data sets. MFA is a symmetrical analysis, in which both data sets play the same role, and exposes correlative structures without any reference to causal relationship (Borcard et al., 2011).

\subsection{Quantitative PCR analysis}

Amplification of the 16S rRNA gene was carried out using the bacteria primers 338f (5'-ACTCCTACGGGAGGCAGCAG-3') and 520r (5'ATTACCGCGGCTGCTGG-3'), as well as the archaeal primers 931f (5'AGGAATTGGCGGGGGAGCA-3') and 1100r (5'-BGGGTCTCGCTCGTTRCC$\left.3^{\prime}\right)$, respectively. Amplification was carried out in triplicate in a RotorGene 3000 cycler (Corbett, Australia) as follows: $10 \mu$ reactions containing $2.5 \mu \mathrm{l}$ template DNA, $2.1 \mu \mathrm{l}$ water, $0.2 \mu \mathrm{l}$ each primer (100 mM stock) and $5 \mu \mathrm{l}$ of $2 \times$ KAPA SYBR Fast Universal qPCR kit (KAPA Biosystems, USA) were cycled ( 40 cycles) at $95^{\circ} \mathrm{C}$ for $10 \mathrm{~s}$, followed by an extension at $62{ }^{\circ} \mathrm{C}$ for $30 \mathrm{~s}$ and an acquisition at $72{ }^{\circ} \mathrm{C}$ for $20 \mathrm{~s}$. The final melting step was carried out from $72{ }^{\circ} \mathrm{C}$ to $95^{\circ} \mathrm{C}$, at a rate of $0.1{ }^{\circ} \mathrm{C} / \mathrm{s}$. Analysis of the results was carried out using the built-in analytical software (micPCR, Bio Molecular Systems, ver. 2.2).

\subsection{Data availability}

Raw sequences were deposited in the European Nucleotide Archive (http://www.ebi.ac.uk/ena) and are available under the accession number PRJEB22952.

\section{Results and discussions}

\subsection{Chemical analysis}

Sediment samples associated with the Uyuk aquifer have been extensively described as permeable and mostly composed of sandy silicates (Dahlkamp, 2013), making the aquifer adequate for ISR processes. However, the high hydraulic conductivity of the aquifer may also allow groundwater to move past the roll front orebody, upand downstream of the zone under ISR exploitation. Table 2 presents the water chemistry measured for the samples involved in this study (a comprehensive list of data is presented in Table SI-A-1).

Groundwater present within the upstream compartment of the aquifer (sample "UP") showed an oxidizing signature (250.2 mV/SHE) before it comes into contact with a more reduced zone (sample "MIN"), with a negative ORP value ( $-281.1 \mathrm{mV} / \mathrm{SHE})$, allowing for uranium precipitation from solution, thereby forming the roll-front orebody structure (Saunders et al., 2016). Sample "DWN" was taken from the reduced zone of the aquifer, located downstream of the mineralized zone $(-14.1 \mathrm{mV} / \mathrm{SHE})$. With the exception of ORP and Fe, both "UP" and "DWN" samples showed a similar chemical signature and close pH values (Table SI-A-1). Samples "IN" and "OUT" were taken at the entrance and the exit (respectively) of the uranium concentration factory. As such, these samples represent a mixture of acidic leachates pumped from various wells in operation. The very low $\mathrm{pH}$ and high ORP values measured in these two samples reflect the conditions induced by ISR mining, and underscore the presence of significant concentrations of metals and metalloids, including $\mathrm{Al}$, as a result of the dissolution of clay particles (up to $832 \mathrm{mg} / \mathrm{l}$ in the 'DWN-1' sample, see Table SI-A-1) (Robin et al., 2015a; Robin et al., 2016). Sulfate and iron showed the highest proportional increase in concentration, with maximal concentrations reaching respectively 22' 810 and $1^{\prime} 210 \mathrm{mg} / \mathrm{l}$ (Table 2). The presence of oxygen is equally a characteristic of these samples, with up to $3.89 \mathrm{mg} / \mathrm{l}$ in the "IN" sample. Samples "IN" and "OUT" were comparable, at least for iron and $\mathrm{pH}$ values, to samples taken by Coupland and Johnson (2004) from an abandoned copper mine in the North of Wales. However, sulfate concentrations were substantially higher in the present study, as a result of the injection of sulfuric acid in the aquifer. Two cases of AMD, reported by Johnson and 
Table 2

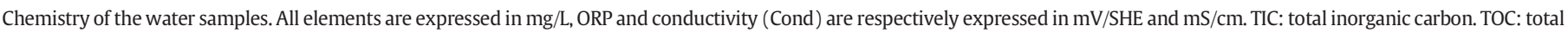
organic carbon.

\begin{tabular}{|c|c|c|c|c|c|c|c|c|c|c|c|c|c|c|c|}
\hline & $\mathrm{pH}$ & ORP & Cond & $\mathrm{Na}$ & $\mathrm{Ca}$ & $\mathrm{Mg}$ & K & $\mathrm{SO}_{4}$ & $\mathrm{Cl}$ & TIC & TOC & $\mathrm{Si}$ & $\mathrm{Fe}$ & $\mathrm{Al}$ & $\mathrm{U}$ \\
\hline UP & 7.6 & 250.2 & 1000 & 106 & 57 & 27 & 4.7 & 183.3 & 125 & 35 & 1.9 & 11 & 0 & 0 & 0 \\
\hline MIN & 7.5 & -281 & 1120 & 116 & 53 & 26 & 4 & 182.2 & 138 & 42 & 2.8 & 12 & 0.1 & 0 & 0 \\
\hline DWN & 8.1 & -14.1 & 1048 & 115 & 48 & 25 & 3.9 & 268.8 & 129 & 34 & 1.3 & 8.9 & 0.3 & 0.1 & 0 \\
\hline UP-acid & 5 & -223 & 2647 & 114 & 127 & 87 & 14 & 1544.7 & 125 & 5.3 & 1 & 13 & 43.2 & 1.1 & 0 \\
\hline DWN2-acid & 3.5 & 120.2 & 7757 & 188 & 300 & 499 & 60 & 10,182 & 126 & 5.7 & 1 & 25 & 479 & 252 & 51 \\
\hline DWN1-acid & 1.7 & 468.8 & 22,810 & 209 & 563 & 762 & 131 & 20,666 & 129 & 2.5 & 1.3 & 136 & 1210 & 832 & 23 \\
\hline OUT & 1.4 & 244.8 & 14,310 & 195 & 523 & 701 & 111 & 19,724 & 133 & 2.8 & 1.1 & 105 & 1140 & 556 & 0 \\
\hline IN & 1.3 & 245.8 & 14,600 & 190 & 519 & 652 & 100 & 19,724 & 168 & 6.7 & 1.6 & 106 & 1070 & 446 & 99 \\
\hline
\end{tabular}

Hallberg (2003), showed a chemistry that was similar to the measured acid solution present in the "IN" and "OUT" samples in terms of sulfate and metals in general, including a sample of the Rio Tinto (Spain) (Amils, 2016). Uranium reached $98.5 \mathrm{mg} / \mathrm{l}$ in "IN" and was absent in "OUT", demonstrating the effectiveness of the retention system based on ion-exchange resins. Uranium concentration measured in "IN" was also similar to those published in other studies on contaminated aquifers and sediments (Wu et al., 2006; Cardenas et al., 2008).

ISR fluids affected wells adjacent to the mineralized section of the aquifer under mining activities. The typical chemical signature present in the "IN" sample was found in wells located in the upstream ("UPacid") and downstream ("DWN1-acid" and "DWN2-acid") sections of the aquifer. 'UP-acid' was affected moderately, showing negative ORP, $\mathrm{pH}>5$, limited amounts of dissolved elements resulting from the dissolution of the geological matrix and no U. Both samples taken downstream of the mining activity zone ('DWN1-acid', "DWN2-acid") were affected to a higher extend by the intrusion of ISR fluid, as shown in Table 2.

\subsection{Microbial quantitative analyses}

16S rRNA gene copy numbers and inference statistics for Bacteria and Archaea are presented in Tables 3 and SI-A-4 respectively. Bacterial cell numbers and diversity indices varied according to the sampling location. The highest copy number was observed in the mineralized area of the aquifer (sample "MIN") with $6.02 \times 10^{6}$ copies of the $16 \mathrm{~S}$ rRNA gene per liter. The sample showing the lowest amount was "DWN", a water sample taken from a pristine area located downstream of the mining area, with $3.41 \times 10^{4}$ copies of the $16 \mathrm{~S}$ rRNA gene per liter. This latter showed the highest cell diversity, with a Fisher's alpha parameter of 80.72. The impact of the ISR process was manifest in the mineralized area, with a significant decrease in the total number of cells. Sample "IN" contained less than $1.70 \times 10^{5}$ copies of the $16 \mathrm{~S}$ rRNA genes, corresponding to a 50 -fold reduction relative to the mineralized (pristine) "MIN" sample. However, the apparent diversity of this sample was large, with a Fisher's alpha parameter of 53.72. The mixing of leach fluids pumped from all wells under mining activity may induce this relatively high diversity value. Furthermore, the uranium processing plant apparently acts as an enrichment system, for more than $6.59 \times 10^{5}$ copies of the 16S rRNA gene were quantified in the "OUT" sample, which is a 5-fold enrichment relative to the "IN" sample. Conversely, this sample exhibited a sharp decline in the apparent diversity as measured with Fisher's alpha parameter (a value of 20). Few AMD studies have characterized cell abundance and diversity in the same manner as was done here. Kimura et al. (2011) showed that significant bacterial cell numbers were present within water samples from an abandoned pyrite mine in Wales. Under acidic conditions ( $\mathrm{pH}$ values varying from 1.85 to 2.30 ), these authors counted from $1 \times 10^{7}$ to $7 \times 10^{8}$ cells per $\mathrm{ml}$ by fluorescence. Edwards et al. (1999) measured very similar numbers in effluents of the Richmond mine (California) using fluorescent probes. In our acidic samples going into and out of the uranium plant ("IN" and "OUT"), the number of $16 S$ rRNA copies were more than 3 and 4 orders of magnitude lower for Bacteria (Table 3) and Archaea (Table SI-A-4), respectively.

The impact of ISR on bacterial communities inhabiting areas adjacent to the production area occurs to varying degrees and is a function of the natural redox zonation inherited from the roll front deposit. This impact is also possibly a function of the time of exposure to the ISR leaching fluids as well as their concentration. Upstream of the mineralized section of the aquifer ( sample "UP-acid"), the impact of the intrusion of acid was moderate, with a lowering of the $\mathrm{pH}$ value from 7.64 to 5.01. For the bacterial community, the impact was significant with a large decrease in cell numbers, as well as in apparent diversity (Table 3 ). Downstream, data showed a moderate decline in cell numbers for sample 'DWN1-acid' and the relative stability of its apparent diversity relative to the mineralized zone (sample "MIN"), despite the significant decrease in the $\mathrm{pH}$ value and a chemical composition very close to the one measured for the "IN" and "OUT" samples. Paradoxically, sample "DWN2-acid", apparently less affected in terms of water chemistry, showed a more significant reduction in cell numbers as well as in the apparent diversity, with one of the lowest Fisher's alpha parameter (30.34).

Archaeal 16S rRNA gene copies were found in very low numbers in all sections of the aquifer. Copies were highest in the "MIN" sample, with $4.90 \times 10^{4}$ copies per liter. This sample also displayed the highest relative bacteria diversity with a Fisher's alpha parameter of 4.64. In the "IN" and "OUT" samples, Archaeal cells were almost absent, reaching barely 787 copies per liter in sample "OUT". In the affected sections of the aquifer, copies varied from 269 to 1'189 copies per liter ("Up-acid" and "DWN2-acid", respectively) (Table SI-A-4). Kock and Schippers (2008) showed that Archaea were sometimes absent from AMD, for being highly sensitive to extreme conditions of temperature and $\mathrm{pH}$.

Table 3

Quantitative PCR on the 16S rDNA genes and inference statistics at the genus level (3\% similarity).

\begin{tabular}{|c|c|c|c|c|c|c|c|c|}
\hline Samples & $\mathrm{pH}$ & Genus richness & OTUs & ACE & CHAO1 & Pielou's evenness & Fisher's alpha & 16S rRNA copies/l \\
\hline UP & 7.64 & 391 & 9833 & 35,080 & 31,088 & 0.67 & 60.14 & $1,639,900$ \\
\hline MIN & 7.49 & 247 & 4399 & 13,394 & 12,031 & 0.49 & 35.09 & $6,017,900$ \\
\hline DWN & 8.09 & 501 & 9743 & 27,489 & 24,780 & 0.59 & 80.72 & 34,100 \\
\hline UP-acid & 5.01 & 276 & 3080 & 9009 & 8155 & 0.51 & 39.94 & 68,400 \\
\hline DWN1-acid & 1.65 & 360 & 6597 & 24,372 & 20,757 & 0.56 & 54.56 & $1,547,900$ \\
\hline DWN2-acid & 3.54 & 218 & 1860 & 5039 & 4590 & 0.34 & 30.34 & 971,000 \\
\hline IN & 1.25 & 355 & 2961 & 8463 & 7250 & 0.36 & 53.72 & 169,700 \\
\hline OUT & 1.35 & 152 & 1070 & 3236 & 2955 & 0.31 & 20.00 & 659,700 \\
\hline
\end{tabular}


With the exception of the members of the Euryarchaeota, other archaeal phyla classically composed a minor fraction of the microbial communities present in AMDs (Chen et al., 2016).

\subsection{Next generation sequencing of the microbial communities}

A simplified table displaying the relative contributions of major phyla is presented (Table 4) and a table summarizing all the phyla is provided in the Appendix (Table SI-A-2). A comprehensive data set measured in this study for the Domains Bacteria and Archaea is presented as an Excel spreadsheet in a separate Excel file (Document SI-B).

Ten major bacterial phyla were sufficient to account for all phyla present, contributing from $68.4 \%$ (sample "UP") to $97.8 \%$ (sample "DWN2-acid") for all sections of the aquifer. The complete list included 54 Phyla, with rare ones, such as AC1, Deferribacteres, and Synergitestes, which were detected in proportions below $1 \%$ (Document SI-B). For the Domain Archaea, three phyla only contributed from $80.4 \%$ (sample "UP") to $99.9 \%$ (sample "OUT") to the communities.

A high proportion of the sequences are affiliated with the Proteobacteria, present in all compartments of the Uyuk aquifer (Tableau 4). This Phylum dominated the autochthonous communities present within the upstream and downstream pristine sections of the aquifer (26.02\% and 16.35\% in "UP" and "DWN" samples, respectively). These pristine sections were populated by a rich diversity of families classically associated with anoxic habitats and involved in fermentation and anaerobic respiration (Fig. 1), such as Desulfobacteraceae, Desulfobulbaceae, Pelobacteraceae, and Syntrophaceae ( $\delta$ Proteobacteria), Comamonadaceae and Rhodocyclaceae ( $\beta$ Proteobacteria) (Florentino et al., 2016). Classes $\alpha-, \varepsilon^{-}$and $\gamma^{-}$ Proteobacteria were present in low proportions only (Document SI-B). The family Rhodocyclaceae was abundant in the "UP" sample with $3.15 \%$ of all sequences. In contrast, the sample from the mineralized zone ("MIN") contained only $8.55 \%$ of sequences affiliated with this phylum, with $7.27 \%$ of $\delta$-Proteobacteria belonging to the above-mentioned families as well as the Syntrophobacteraceae (2.22\%), which appeared only in this section of the aquifer. In the zones affected by ISR fluids, the predominance of Proteobacteria was even greater, with a maximum of $68.84 \%$ of all sequences for sample "DWN2-acid". Sample "UP-acid" was characterized by the presence of the highest proportion of $\beta$-Proteobacteria (13.21\%) with Gallionellaceae (3.73\%) and Hydrogenophilaceae (Thiobacillus sp., 3.45\%) (Document SI-B). This sample displayed equally significant proportions of organisms such as Acidithiobacillus sp., a y-Proteobacteria present in $2.27 \%$, which is commonly identified within acidophilic sulfur-oxidizing biota (MéndezGarcía et al., 2015). In contrast, low contributions ( $<1 \%)$ of sequences affiliated with neutrophilic $\delta$-Proteobacteria were observed. The apparent mixing of organisms typically associated with distinct environments may have resulted from the mixing of fluid from the adjacent ISR production cell, and the reduced and neutrophilic water from the upstream section of the aquifer. This mixing resulted in the formation of an ecotone, confirmed by the presence of Gallionella sp., which typically grows in microaerophilic water laden with ferrous iron (Hallbeck and Pedersen, 2005). In downstream sections of the aquifer affected by the ISR process, the predominance in Proteobacteria was evidenced by large contributions from $\mathrm{\gamma}$-Proteobacteria, reaching $35.99 \%$ and $66.49 \%$ of all sequences in 'DWN1-acid' and "DWN2-acid", respectively. The phylogeny of the vast majority of these sequences was unknown ( $23.94 \%$ and $57.78 \%$, respectively), the rest being shared between sequences affiliated to Alteromonadales and Pseudomonadales (Fig. 1).

Samples "IN" and "OUT" exhibit a distinct microbial structure relative to the phylum Proteobacteria. Specifically, sequences affiliated with the family Acidithiobacillaceae and the genus Acidithiobacillus representing $61.81 \%$ and $22.59 \%$ of the sequences, respectively. This genus is composed of strictly aerobic and acidophilic organisms that use reduced sulfur to support autotrophic growth (Nuñez et al., 2017). Some strains have been shown to use ferrous iron as well as U(IV) as a source of electrons and energy (Kelly and Wood, 2015). The majority of these sequences could not be assigned at the species level, and only a minor fraction was affiliated to At. caldus and At. albertensis. Acidithiobacillus sp. was also present in smaller proportion in the upstream and downstream affected sections of the aquifer, confirming the intrusion of ISR fluids. In samples "IN" and "OUT", respectively $3.29 \%$ and $7.10 \%$ of all sequences were affiliated with mitochondrial sequences (Document SI-B). The presence of sequences affiliated with eukaryotic cells (unclassified) in the samples strongly affected by acid confirmed the results obtained earlier by Kock and Schippers (2008) in the analysis of AMD samples.

Sequences affiliated with the Phylum Firmicutes (Fig. 2) showed the clear predominance of the Sulfobacillaceae (genus Sulfobacillus sp.) in samples "IN" (6.25\%) and "OUT" (17.41\%), as well as in the DWN1acid sample (19.04\%) (Document SI-B). When the impact of the acidic fluid was moderate, with $\mathrm{pH}$ values $>3$, the $\mathrm{Fe}$ (II)-oxidizing Alicyclobacillus sp. was most abundant, as in the "UP-acid" and "DWN2-acid" samples. This organism is a facultative anaerobe and mixotroph, providing a strong ecological advantage in these sections of the aquifer (Yahya et al., 2008; Chen et al., 2016).

The distribution of individual families within the Phylum Firmicutes was highly dependent on the spatial location and the redox zonation relative to the mineralized zone. In the "UP" community, the Firmicutes are represented by Peptococcaceae (7.65\%), with representatives of the genus Desulfurispora sp., which are endospore-forming, sulfate reducers. In contrast, the "DWN" sample was heterogeneous with approximately equal contributions from a number of families, Peptococcaceae, Streptococcaceae and Erysipelotrichaceae. Sample "MIN" showed a

Table 4

List of major phyla and their relative contributions (in \%) to the Bacterial and Archaean communities.

\begin{tabular}{|c|c|c|c|c|c|c|c|c|}
\hline & UP & MIN & DWN & UP-acid & DWN1-acid & DWN2-acid & IN & OUT \\
\hline Actinobacteria & 1.17 & 0.46 & 5.41 & 9.90 & 8.75 & 10.75 & 5.61 & 2.06 \\
\hline Bacteroidetes & 7.26 & 9.03 & 7.06 & 22.09 & 10.35 & 0.82 & 3.75 & 0.21 \\
\hline Chlorobi & 6.28 & 0.49 & 2.63 & 6.41 & 0.38 & 0.37 & 0.06 & 0.01 \\
\hline Chloroflexi & 6.85 & 0.22 & 11.02 & 0.37 & 0.66 & 0.27 & 0.48 & 0.02 \\
\hline Firmicutes & 12.04 & 3.04 & 8.00 & 4.22 & 24.50 & 10.67 & 9.20 & 17.95 \\
\hline Lentisphaerae & 0.03 & 28.92 & 0.01 & 0 & 0.04 & 0.02 & 0.03 & 0 \\
\hline Nitrospirae & 1.37 & 0.38 & 11.64 & 0.09 & 0 & 0.15 & 0.13 & 46.63 \\
\hline OD1 & 5.15 & 8.62 & 0.36 & 0.61 & 0.02 & 0.75 & 0.03 & 0 \\
\hline OP11 & 2.28 & 9.81 & 0.21 & 0.66 & 0.01 & 5.18 & 0.02 & 0 \\
\hline Proteobacteria & 26.02 & 8.55 & 16.35 & 25.14 & 44.89 & 68.84 & 76.78 & 30.92 \\
\hline Unclass. Bacteria & 18.75 & 19.92 & 32.29 & 27.83 & 4.97 & 1.76 & 1.35 & 1.92 \\
\hline Crenarchaeota & 10.83 & 1.96 & 19.72 & 13.55 & 6.66 & 5.58 & 4.91 & 4.16 \\
\hline Euryarchaeota & 44.56 & 19.54 & 70.41 & 85.60 & 92.92 & 92.93 & 94.52 & 95.57 \\
\hline [Parvarchaeota] & 25.03 & 70.47 & 3.66 & 0.00 & 0.18 & 1.17 & 0.40 & 0.13 \\
\hline Unclass. Archaea & 19.58 & 8.02 & 6.21 & 0.84 & 0.24 & 0.32 & 0.17 & 0.14 \\
\hline
\end{tabular}




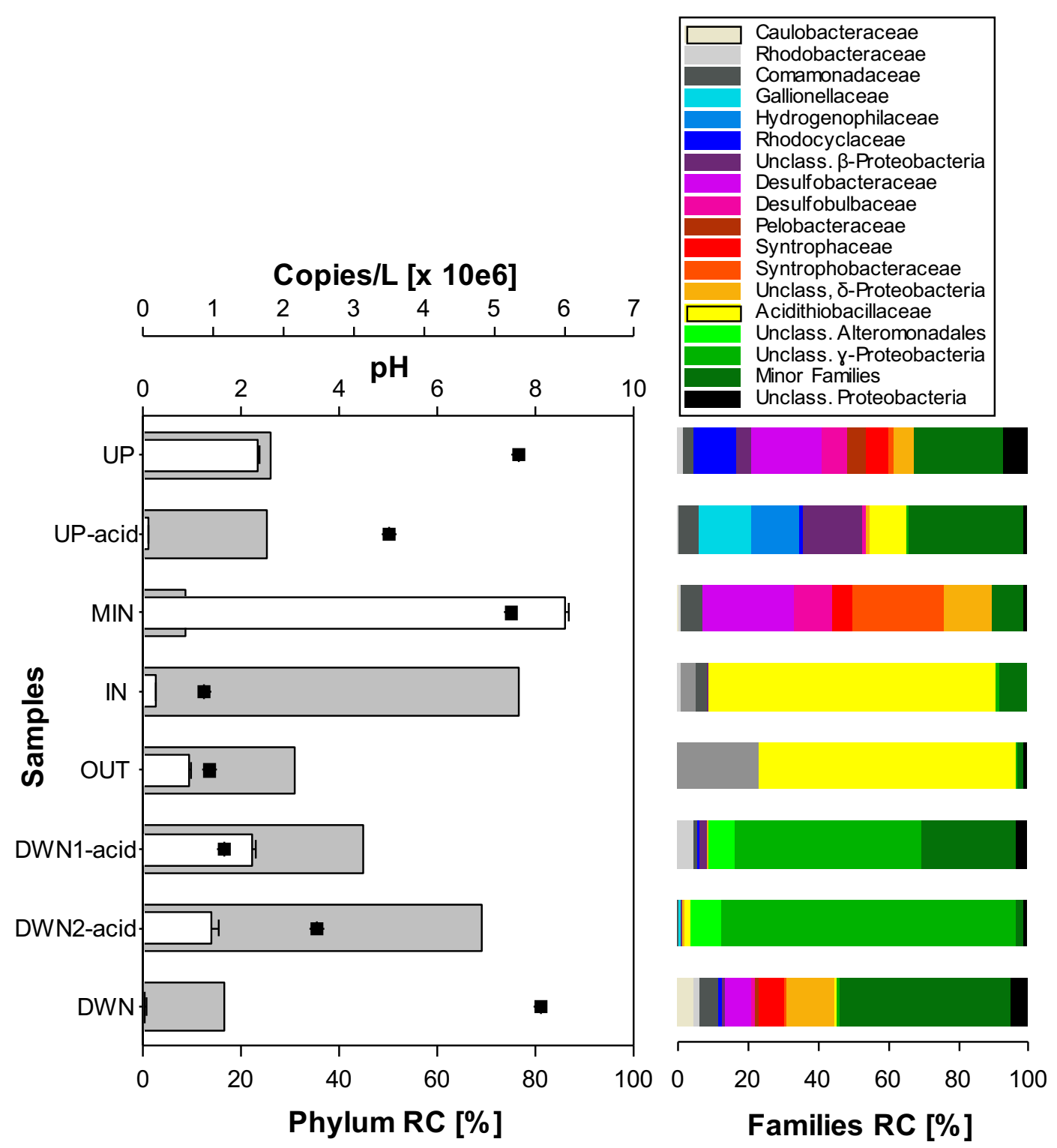

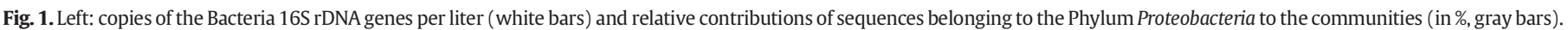
Black squares: pH values. Right: relative contributions (in \%) of Families present within the Phylum.

different pattern, with the large dominance of members affiliated with the Ruminococcaceae (1.69\%). This sample also displayed the highest proportion of the phylum Lentisphaerae (28.92\%), which was almost absent in all other samples (Fig. SI-A-7).

\subsection{Comparative analysis with AMD-related communities}

Comparison with data collected worldwide showed that the immediate area receiving sulfuric acid was chemically similar to acid mining drainage (AMD). However, the ISR samples are comparatively different with respect to the high nitrogen and phosphorus contents (Table SI-A1), which is not typical of AMD systems (Baker and Banfield, 2003), due to the precipitation of ferric phosphate (Falagán et al., 2014). These limitations can be mitigated in AMD by the fixation of nitrogen, which was found in the genus Leptospirillum and Acidithiobacillus, providing these genera with an ecological advantage and resulting in their abundance (Huang et al., 2016). The analysis carried out in the present study showed that phosphorus and nitrogen compounds were absent in the water samples taken from the pristine sections of the aquifer, despite low amounts present within minerals and organic compounds within the aquifer matrix (data not shown). Intrusion of high concentrations of both compounds with the incoming of ISR fluids in the affected sections of the aquifer is likely to explain the reason for the presence of high 165 rRNA copy numbers as well as the persistence of highly diversified microbial communities.

Microbial communities populating AMDs show strong disparities in their phylogenetic make-up (Huang et al., 2016). The biomes found worldwide harbor abundant acidophilic chemolithotrophic organisms belonging to the Phyla Proteobacteria, Nitrospira, Actinobacteria, Firmicutes, Acidobacteria, Aquificae and the candidate Phylum TM7 (Chen et al., 2016). However, the relative proportion of each phylum as well as the relative contributions of each species within the phylum strongly depended on local environmental factors (Kuang et al., 2013). These discrepancies were found at a high phylogenetic level (phylum), but also at low level, with the presence of specific and local phylotypes, as it was the case for Acidithiobacillus sp. and Sulfobacillus sp. (Justice et al., 2014; Nuñez et al., 2017). In the present study, Sulfobacillus sp. was present in samples "IN" and "OUT", as well as in all samples affected by ISR fluids. Some Sulfobacillus species are mixotrophs, which could provide them with the ability to live in a wide range of environmental 

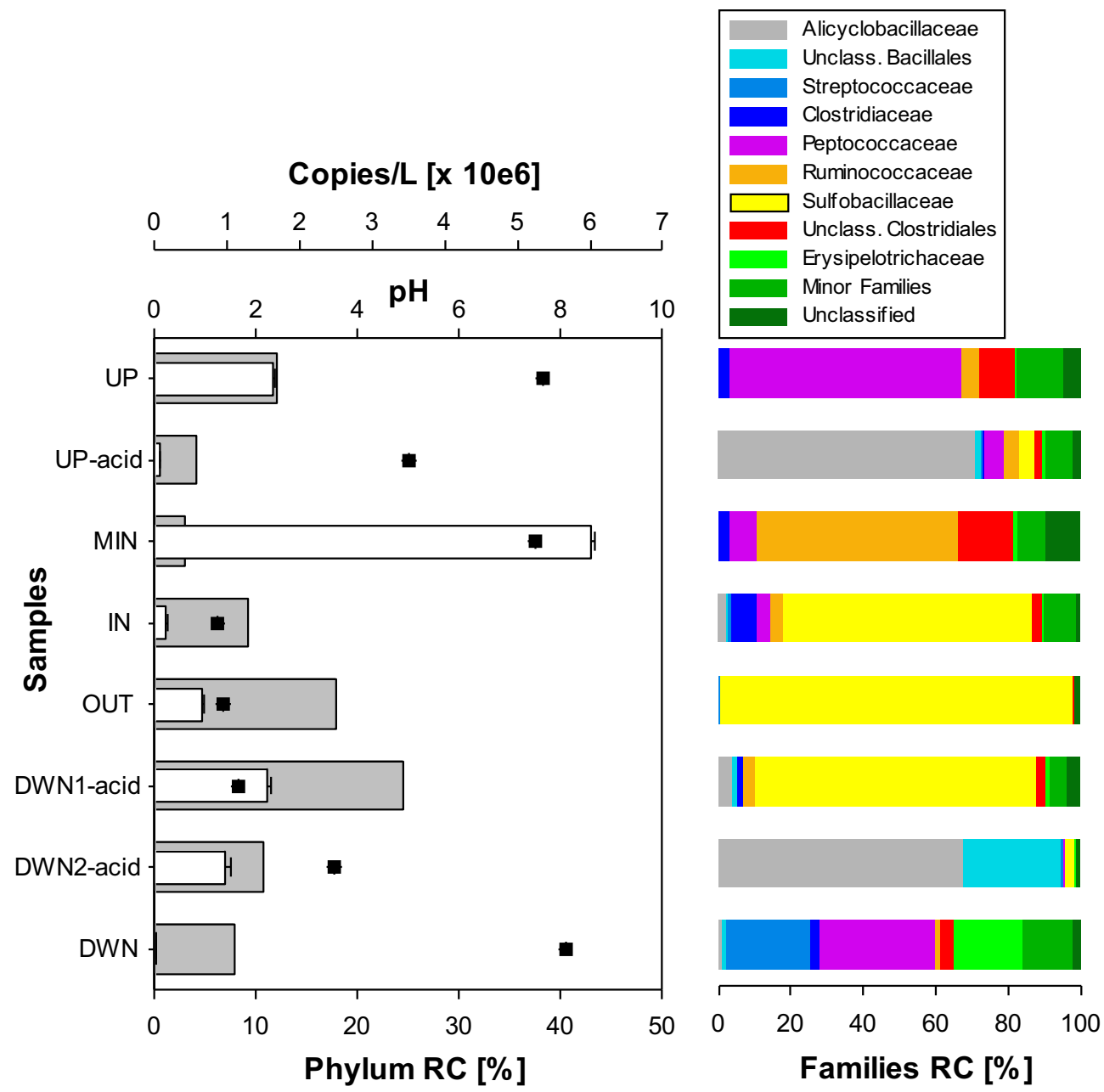

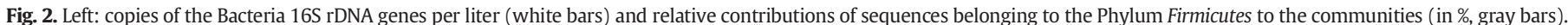
Black squares: pH values. Right: relative contributions (in \%) of Families present within the Phylum.

conditions. Others are reported to be able to use alternative electron acceptors, such as nitrate, and could potentially contribute to the acidification of their habitat in absence of oxygen (Justice et al., 2014). Leptospirillum sp. contributed up to $46.52 \%$ of all sequences found in the "OUT" samples, making this genus the highest contributor within this sample (Fig. 4). This genus however contributed marginally to the communities present within the affected sections of the aquifer, with $0.13 \%$ and $0.04 \%$ in samples "IN" and "UP-acid", respectively (Document SI-B). 16S rRNA gene copy numbers increased almost four fold when passing through the uranium processing plant, from 1.69E5 to 6.59E5 copies per liter, suggesting that the plant offers a highly favorable environment for Leptospirillum (Table 3). This may be because of the corrosion of steel pipes within the U concentration plant, which releases Fe (II), the substrate for aerobic iron oxidation by Leptospirillum. As for Sulfobacillus sp., data obtained here cannot however prove with certainty that Leptospirillum sp. contributed to the oxidation of the native $\mathrm{Fe}(\mathrm{II})$ within the aquifer, and therefore contributed to the mobilization of $\mathrm{U}(\mathrm{VI})$.

Alicyclobacillus sp. (and Acidomicrobiaceae in general, with a maximum of $7.25 \%$ in 'DWN2-acid') were present preferentially in the affected sections of the aquifer (Fig. 2). Members of this genus were documented as heterotrophs or chemolithoautotrophs in mine environments or AMD treatment plants (Chen et al., 2016). In the present study, results showed that these organisms were less abundant in the strongly oxidative and acidic conditions of ISR. Dissimilatory sulfate reducers belonging to the Phylum Nitrospirae were found at very low contributions in sections of the aquifer affected by the ISR fluids, and reached up to $11.16 \%$ of all sequences in 'DWN1-acid'. Members of the genus Thermodesulfovibrio can use thiosulfate and/or sulfite and nitrate as alternative electron acceptors. All isolates are also capable of a chemolithoheterotrophic lifestyle using $\mathrm{H}_{2}$ as an electron donor and acetate as a carbon source (Daims, 2014).

Most of the Archaea identified in the present study showed low abundances. Ferroplasma sp. (Family Ferroplasmaceae) was the only purely acidophilic genus belonging to the domain Archaea, and was found solely in samples "IN" and "OUT" (Fig. SI-A-9). As it was the case for Sulfobacillus sp. and Leptospirillum sp., Ferroplasma sp. was enriched during the passage of the ISR fluid in the pipes of the uranium concentration plant. The relative proportion of 16S rRNA sequences was increased, going from $0.45 \%$ in "IN" to more than $31.15 \%$ in "OUT". Samples taken from "IN" and "OUT", as well as from the affected sections of the aquifer were composed of ca. $85 \%$ to $95 \%$ of sequences that were affiliated with the phylum Euryarchaeota. These methanogens were affiliated with organisms belonging to the families Methanobacteriaceae, Methanospirillaceae and especially Methanosaetaceae. Among the latter, genus Methanosaeta sp. was particularly abundant in acid samples, contributing 51.04\% of all Archaea sequences present in the sample "IN" (Fig. SI-A-9). Sections of the native aquifer were populated of Euryarchaeota (between 19 and 69\%) in addition to the relative proportions of sequences that are affiliated to the phylum Parvarchaeota (Fig. SI-A-10), as it was the case for sample "MIN" with unknown sequences 

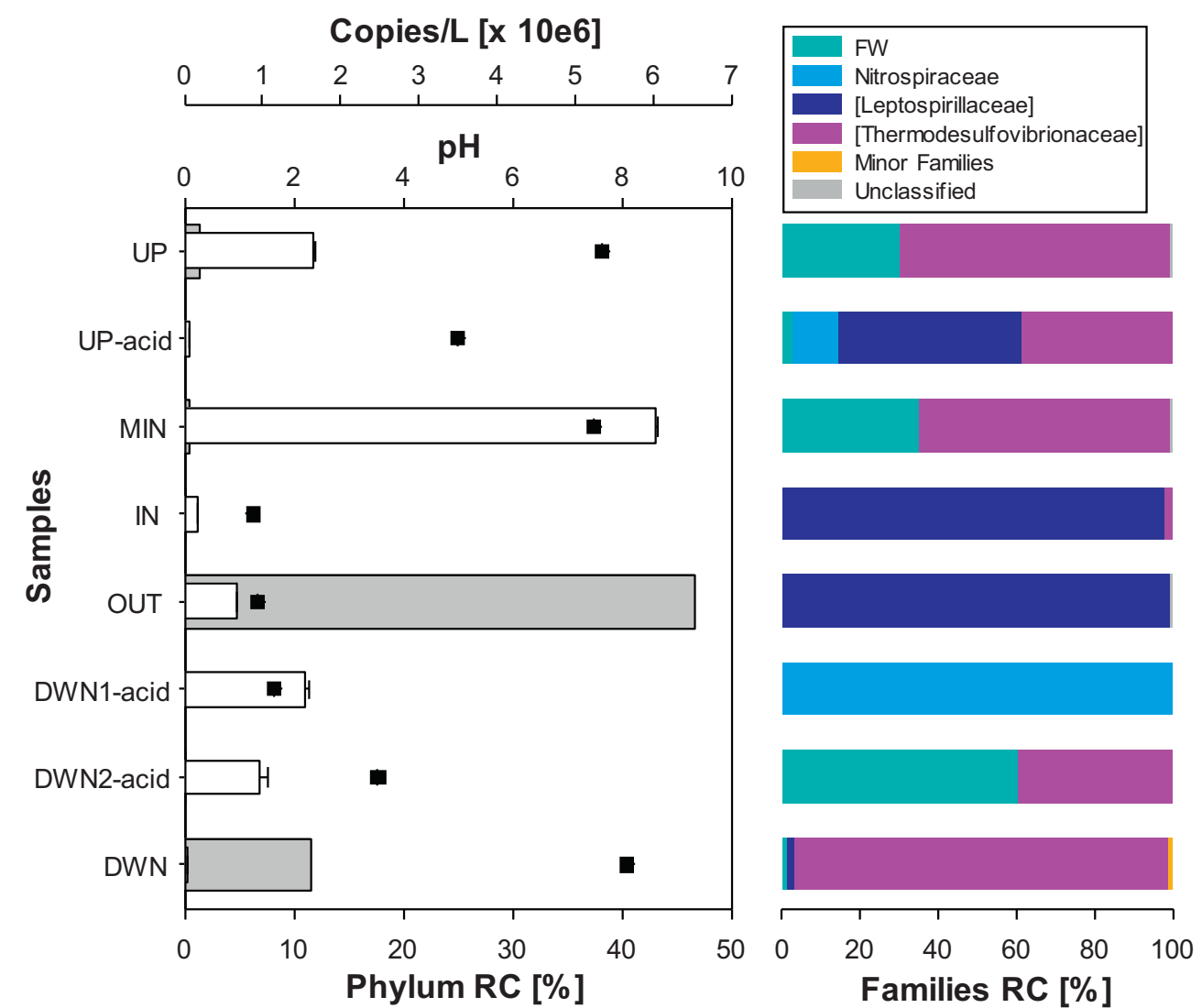

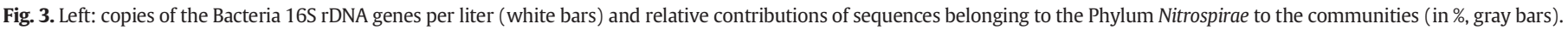
Black squares: pH values. Right: relative contributions (in \%) of Families present within the Phylum.

affiliated to the Orders WCHD3-30 and YLA114 (66.03\% of the sequences).

\subsection{Correlations between community structures and chemical data sets}

At the family level, Bacteria and Archaea were statistically correlated principally with elements linked with $\mathrm{pH}$, cationic exchange (Robin et al., 2015b) and dissolution mechanisms, such as calcium, iron, magnesium, manganese, titanium and zinc (Table SI-A-3). No significant correlation were present with redox (ORP), dissolved oxygen, aluminum and total organic carbon (TOC). In comparison, correlation between $\mathrm{pH}$ value and community composition was identified in several habitats affected by AMD (Kuang et al., 2013). In a recent review, Huang et al. (2016) presented seven studies for which this statistical correlation was demonstrated. However, these authors also identified two studies showing a statistical correlation between metal concentrations and microbial communities in water samples affected by AMD (García-Moyano et al., 2012; Yang et al., 2014).
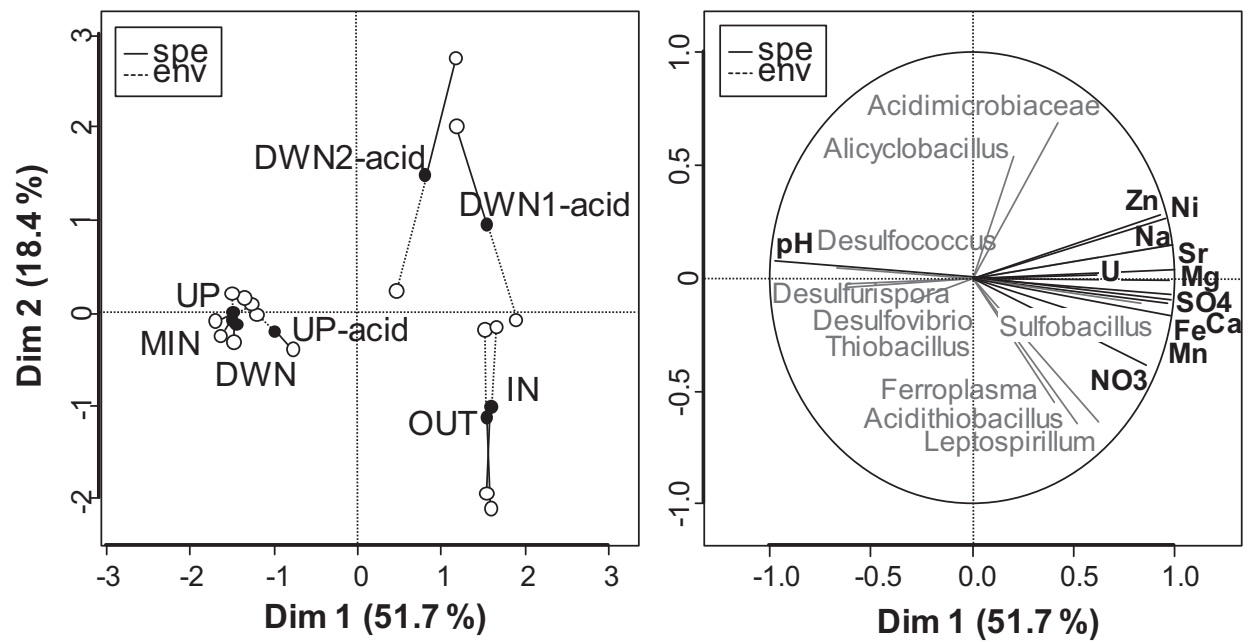

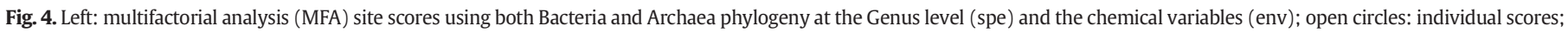
full circles: sample score centroid. Right: correlations between chemical data and MFA site scores. Variables and Genus showing statistically significant correlations are displayed only. 
Results from the MFA analysis (Fig. 3, left) shows that three clusters of samples are formed, separated mainly on Axis 1 (explaining $51.7 \%$ of the variance), which is interpreted as the expression of the $\mathrm{pH}$ variable (Fig. 3, right). The first cluster includes all the samples from the native aquifer ('UP', 'DWN', and 'MIN'), as well as the affected sample "UPacid". Short distances separate the centroids of the pristine sample scores, supporting the statistical similarity between both set of data. Sample 'UP-acid' is located close to these samples. This sample is characterized by the presence of genera typically associated with AMD, as well as those typical of anoxic and reduced areas (the latter were more abundant). Such a mixed community may form with the mixing of relatively low amounts of ISR fluid, rich in oxygen, organic matter, nitrogen and phosphorus within the reduced water present in the native sections of the pristine aquifer. This juxtaposition of microbial genera potentially represents evidence for a certain degree of resilience of the autochthonous community, with which allochthonous acidophilic organisms are blended. The resulting mixed biome is likely to compose an ecotone, which could contribute potentially to the natural attenuation of the aquifer.

The second cluster shown by the MFA analysis consists of samples related to the uranium concentration plant ('IN' and 'OUT'). Both samples showed greater distances between chemical and microbiological components, possibly reflecting the mixing of multiple sources reaching the uranium concentration plant. The third group is composed of the two affected samples located downstream of the mineralized area under ISR activity. Here again, both samples showed large distances between biological and chemical components. These distances may be interpreted as the impact of the mixing of ISR fluids within the reduced section of the aquifer, inducing an imbalance between community and chemical compositions.

The three clusters mentioned above corresponded to three major groups of Families (Fig. 3, right), sharing specific oxidation or reduction activities. The first cluster, representing pristine conditions and neutral $\mathrm{pH}$ values, included hetetotrophic organisms typically found in reductive habitats, such as the genera Desulfurispora, Desulfovibrio and Desulfococcus. In contrast, the second cluster harbored representatives of the genera Ferroplasma, Acidithiobacillus and Leptospirillum, which are typically present at low $\mathrm{pH}$ values and at high concentrations of dissolution products. The mixotrophic genus Sulfobacillus sp. was not closely associated with this group, probably due to its ability to oxidize both reduced sulfur and iron compounds. The third cluster of organisms was related to representatives of the affected aquifer section located downstream, such as members of the Family Acidimicrobiaceae and genus Alicyclobacillus.

\section{Conclusions}

In this study, we provide an in-depth analysis of microbial communities affected by ISR mining. As expected, the addition of acid strongly affected the chemistry and the associated microbial communities and this change was observable even at the phylum level. The taxa involved in the acidification process followed a strong niche differentiation, including the implication of deeply diverging bacterial guilds. This result indicated that high bacterial taxa distribution was ecologically coherent with ecosystem functioning. $\mathrm{pH}$ was the main driving force for the chemical and microbial community changes observed in the aquifer. Bacterial diversity and numbers of the original neutrophilic communities were decreased in favor of acidophilic species in ISR areas. Sections affected by ISR fluids showed specific characteristics, halfway between the two, resulting in the formation of an ecotone showing microbial assemblages able to cope with limited amounts of mining leach fluid. This result suggests an intrinsic natural attenuation capacity of the aquifer. However, it was not possible to quantify this capacity based on this study. Sulfuric acid injection liberated metals and increased the amount of sulfate within the aquifer, thus creating conditions that were similar to AMD. Consequently, the resulting microbial community harbored some genera typically associated with AMD. This affords a considerable advantage to future experimental design, as AMD is a well-studied system. The similarity of the microbial community between the acidic samples from Kazakhstan and AMD suggested that the lack of carbon within the subsurface would retard full natural attenuation. Thus, biostimulation of the metal- and sulfate-reducing guilds may be promoted with the addition of an adequate carbon sources (e.g., ethanol and glycerol). Future work should focus on ways to promote specifically the growth of metal- and sulfate-reducers capable of raising $\mathrm{pH}$ and precipitating metals and uranium from the acidic solutions, using known techniques related to AMD remediation.

\section{Competing Interest Statement}

The authors declare no competing interests.

\section{Acknowledgement}

EPFL and Areva Mines (France) funded the research described here. We acknowledge Emmanuelle Rohrbach, Brian C. Reinsch and the CEL team at EPFL for their technical assistance, Thierry Lefebvre and Olivier Regnault and local field technicians at KATCO for their precious contribution to the sampling process, as well as Evelyne Ruchti (Blueprint Design) for the design of the graphical abstract. Mention of trade names and commercial products does not constitute recommendation for use.

\section{Appendix A. Supplementary data}

Supplementary data to this article can be found online at https://doi. org/10.1016/j.scitotenv.2018.01.321.

\section{References}

Alrakabi, M., Singh, G., Bhalla, A., Kumar, S., Srivastava, A., Rai, B., Singh, N., Shahi, J.S Mehta, D., 2012. Study of uranium contamination of ground water in Punjab state in India using X-ray fluorescence technique. J. Radioanal. Nucl. Chem. 294:221-227. https://doi.org/10.1007/s10967-011-1585-X.

Amils, R., 2016. Lessons learned from thirty years of geomicrobiological studies of Río Tinto. Res. Microbiol. 167 (7), 539-545.

Baker, B.J., Banfield, J.F., 2003. Microbial communities in acid mine drainage. FEMS Microbiol. Ecol. 44 (2), 139-152.

Belitz, K., Fram, M.S., Johnson, T.D., 2015. Metrics for assessing the quality of groundwater used for public supply, CA, USA: equivalent-population and area. Environ. Sci. Technol. 49:8330-8338. https://doi.org/10.1021/acs.est.5b00265.

Benes, V., Boitsov, A.V., Fuzlullin, M., Hunter, J., Mays, W., Novak, J., Underhill, D.H., 2001 Manual of Acid In Situ Leach Uranium Mining Technology. International Atomic Energy Agency, Vienna, Austria.

Bernier-Latmani, R., Vecchia, E.D., Junier, P. Lezama-Pacheco, J.S., Veeramani, H. Suvorova, E.I., Sharp, J.O., Wigginton, N.S., Bargar, J.R., 2010. Non-uraninite products of microbial U(VI) reduction. Environ. Sci. Technol. 44:9456-9462. https://doi.org/ 10.1021/es101675a.

Borcard, D., Gillet, F., Legendre, P., 2011. Numerical ecology with R. Use R. Springer Sci. Media https://doi.org/10.1007/978-1-4419-7976-6_1.

Cai, Y., Sun, Y., 2011. ESPRIT-tree: hierarchical clustering analysis of millions of 16S rRNA in quasilinear computational time. Nucleic Acids Res. 39, e95.

Cardenas, E., Wu, W.M., Leigh, M.B., Carley, J., Carroll, S., Gentry, T., Kitanidis, P.K., 2008. Microbial communities in contaminated sediments, associated with bioremediation of uranium to submicromolar levels. Appl. Environ. Microbiol. 74 (12), 3718-3729.

Chen, L.X., Huang, L.N., Méndez-García, C., Kuang, J.L., Hua, Z.S., Liu, J., Shu, W.S., 2016. Microbial communities, processes and functions in acid mine drainage ecosystems. Curr. Opin. Biotechnol. 38, 150-158.

Coupland, K., Johnson, D.B., 2004. Geochemistry and microbiology of an impounded subterranean acidic water body at Mynydd Parys, Anglesey, Wales. Geobiology 2 (2), 77-86.

Dahlkamp, F.J., 2009. Part I: Typology of Uranium Deposits. In Uranium Deposits of the World (pp. 451-452)Springer, Berlin Heidelberg.

Dahlkamp, F.J., 2013. Uranium ore deposits. Springer Science \& Business Media.

Daims, H., 2014. The Family Nitrospiraceae. In The Prokaryotes (pp. 733-749)Springer, Berlin Heidelberg.

Diaby, N., Dold, B., Rohrbach, E., Holliger, C., Rossi, P., 2015. Temporal evolution of bacterial communities associated with the in situ wetland-based remediation of a marine shore porphyry copper deposit. Sci. Total Environ. 533, 110-121.

Dopson, M., Johnson, D.B., 2012. Biodiversity, metabolism and applications of acidophilic sulfur-metabolizing microorganisms. Environ. Microbiol. 14 (10), 2620-2631.

Edgar, R.C., Haas, B.J., Clemente, J.C., Quince, C., Knight, R., 2011. UCHIME improves sensitivity and speed of chimera detection. Bioinformatics 27, 2194-2200. 
Edwards, K.J., Gihring, T.M., Banfield, J.F., 1999. Seasonal variations in microbial populations and environmental conditions in an extreme acid mine drainage environment. Appl. Environ. Microbiol. 65 (8), 3627-3632.

Falagán, C., Sánchez-España, J., Johnson, D.B., 2014. New insights into the biogeochemistry of extremely acidic environments revealed by a combined cultivation-based and culture-independent study of two stratified pit lakes. FEMS Microbiol. Ecol. 87 (1), 231-243.

Florentino, A.P., Weijma, J., Stams, A.J., Sánchez-Andrea, I., 2016. Ecophysiology and application of acidophilic sulfur-reducing microorganisms. Biotechnology of Extremophiles. Springer International Publishing, pp. 141-175.

García-Moyano, A., Gonzalez-Toril, E., Aguilera, Á., Amils, R., 2012. Comparative microbial ecology study of the sediments and the water column of the Río Tinto, an extreme acidic environment. FEMS Microbiol. Ecol. 81 (2), 303-314.

Hallbeck, L.E.L., Pedersen, K., 2005. Gallionella. Bergey's Manual of Systematics of Archaea and Bacteria.

Huang, L.N., Kuang, J.L., Shu, W.S., 2016. Microbial ecology and evolution in the acid mine drainage model system. Trends Microbiol. 24 (7), 581-593.

Huse, S.M., Welch, D.M., Morrison, H.G., Sogin, M.L., 2010. Ironing out the wrinkles in the rare biosphere through improved OTU clustering. Environ. Microbiol. 12, 1889-1898.

Johnson, D.B., 2012. Geomicrobiology of extremely acidic subsurface environments. FEMS Microbiol. Ecol. 81 (1), 2-12.

Johnson, D.B., Hallberg, K.B., 2003. The microbiology of acidic mine waters. Res. Microbiol. 154 (7), 466-473.

Justice, N.B., Norman, A., Brown, C.T., Singh, A., Thomas, B.C., Banfield, J.F., 2014. Comparison of environmental and isolate Sulfobacillus genomes reveals diverse carbon, sulfur, nitrogen, and hydrogen metabolisms. BMC Genomics 15 (1), 1107.

Kelly, D.P., Wood, A.P., 2015. Acidithiobacillus. Bergey's Manual of Systematics of Archaea and Bacteria, pp. 1-5.

Kimura, S., Bryan, C.G., Hallberg, K.B., Johnson, D.B., 2011. Biodiversity and geochemistry of an extremely acidic, low-temperature subterranean environment sustained by chemolithotrophy. Environ. Microbiol. 13 (8), 2092-2104.

Kock, D., Schippers, A., 2008. Quantitative microbial community analysis of three different sulfidic mine tailing dumps generating acid mine drainage. Appl. Environ. Microbiol. 74 (16), 5211-5219.

Kuang, J.L., Huang, L.N., Chen, L.X., Hua, Z.S., Li, S.J., Hu, M., Li, J.T., Shu, W.S., 2013. Contemporary environmental variation determines microbial diversity patterns in acid mine drainage. ISME J. 7 (5), 1038-1050.

Méndez-García, C., Peláez, A.I., Mesa, V., Sánchez, J., Golyshina, O.V., Ferrer, M., 2015. Microbial diversity and metabolic networks in acid mine drainage habitats. Front. Microbiol. 6, 475

Morrell, J.S., 2013. In: Jackson, M.J. (Ed.), Uranium processing and properties. Springer.

Newsome, L., Morris, K., Shaw, S., Trivedi, D., Lloyd, J.R., 2015. The stability of microbially reduced U (IV); impact of residual electron donor and sediment ageing. Chem. Geol. 409, 125-135.

Nuñez, H., Moya-Beltrán, A., Covarrubias, P.C., Issotta, F., Cardenas, J.P., Gonzalez, M. Atavales, J., Acuña, L.G., Johnson, B.D., Quatrini, R., 2017. Molecular systematics of the genus Acidithiobacillus: insights into the phylogenetic structure and diversification of the taxon. Front. Microbiol. 7 (5), 1038-1050.

Quast, C., Pruesse, E., Yilmaz, P., Gerken, J., Schweer, T., Yarza, P., Peplies, J., Glöckner, F.O. 2013. The SILVA ribosomal RNA gene database project: improved data processing and web-based tools. Nucleic Acids Res. 41 (D1), D590-D596.

R Development Core Team, 2009. R: a language and environment for statistical computing. http://www.R-project.org.

Rawlings, D.E., 2002. Heavy metal mining using microbes 1. Annu. Rev. Microbiol. 56 (1) $65-91$.

Robin, V., Hebert, B., Beaufort, D., Sardini, P., Tertre, E., Regnault, O., Descostes, M., 2015a. Occurrence of authigenic beidellite in the Eocene sandy sediments of the Chu-Saryssu basin (Kazakhstan). Sediment. Geol. 321, 39-48.
Robin, V., Tertre, E., Beaufort, D., Regnault O Sardini, P., Descostes, M., 2015b. Ion exchange reactions of major inorganic cations $(\mathrm{H}+, \mathrm{Na}+, \mathrm{Ca} 2+, \mathrm{Mg} 2+$ and $\mathrm{K}+)$ on beidellite: experimental results and new thermodynamic database. Towards a better prediction of contaminant mobility in natural environments. Appl. Geochem. 59, $74-84$

Robin, V., Tertre, E., Regnault, O., Descostes, M., 2016. Dissolution of beidellite in acidic solutions: new insights on interface reactions and effect of crystal chemistry on smectite reactivity. Geochim. Cosmochim. Acta 180, 97-108.

Romero-González, M., Nwaobi, B.C., Hufton, J.M., Gilmour, D.J., 2016. Ex-situ bioremediation of $\mathrm{U}(\mathrm{VI})$ from contaminated mine water using Acidithiobacillus ferrooxidans strains. Front. Environ. Sci. 4, 39

Saunders, J.A., Pivetz, B.E., Voorhies, N., Wilkin, R.T., 2016. Potential aquifer vulnerability in regions down-gradient from uranium in situ recovery (ISR) sites. J. Environ. Manag. 183, 67-83.

Schloss, P.D. Westcott, S.L, Ryabin, T. et al, 2009. Introducing mothur: open-source, platform-independent, community-supported software for describing and comparing microbial communities. Appl. Environ. Microbiol. 75, 7537-7541.

Tarnawski, S.E., Rossi, P., Brennerova, M.V., Stavelova, M., Holliger, C., 2016. Validation of an integrative methodology to assess and monitor reductive dechlorination of chlorinated ethenes in contaminated aquifers. Front. Environ. Sci. 4, 7.

Taylor, G., Farrington, V., Woods, P., Ring, R., Molloy, R., 2004. Review of Environmental Impacts of the Acid In-Situ Leach Uranium Mining Process. In CSIRO Land and Water Client Report (p. 60)CSIRO Clayton, Victoria.

Volant, A., Bruneel, O., Desoeuvre, A., Héry, M., Casiot, C., Bru, N., Delpoux, S., Fahy, A., Javerliat, F., Bouchez, O., Duran, R., Bertin, P., Elbaz-Poulichet, F., Lauga, B., 2014. Diversity and spatiotemporal dynamics of bacterial communities: physicochemical and other drivers along an acid mine drainage. FEMS Microbiol. Ecol. 90 (1), 247-263.

Wall, J.D., Krumholz, L.R., 2006. Uranium reduction. Annu. Rev. Microbiol. 60:149-166. https://doi.org/10.1146/annurev.micro.59.030804.121357.

Watson, D.B., Wu, W.M., Mehlhorn, T., Tang, G., Earles, J., Lowe, K., Gihirng, T.M., Zhang, G., Philips, J., Boyanov, M.I., Spalding, B.P., Schadt, C., Kemner, K.M., Criddle, C.S., Jardine, P.M., Brooks, S.C., 2013. In situ bioremediation of uranium with emulsified vegetable oil as the electron donor. Environ. Sci. Technol. 47 (12), 6440-6448.

Williams, K.H., Bargar, J.R., Lloyd, J.R., Lovley, D.R., 2013. Bioremediation of uranium-contaminated groundwater: a systems approach to subsurface biogeochemistry. Curr. Opin. Biotechnol. 24 (3), 489-497.

World Nuclear Association, 2016. In Situ Leach (ISL) Mining of Uranium. WNA website. http://www.world-nuclear.org/info/Nuclear-Fuel-Cycle/Mining-of-Uranium/In-SituLeach-Mining-of-Uranium/.

Wu, W.M., Carley, J., Gentry, T., Ginder-Vogel, M.A., Fienen, M., Mehlhorn, T., Yan, H., Caroll, S., Pace, M.N., Nyman, J., Luo, J., Gentile, M.E., Fields, M.W., Hickey, R.F., Gu, B., Watson, D., Cirpka, O.A., Zhou, J., Fendorf, S., Kitanidis, P.K., Jardine, P.M., Criddle, C.S., 2006. Pilot-scale in situ bioremedation of uranium in a highly contaminated aquifer. 2. Reduction of $\mathrm{U}(\mathrm{VI})$ and geochemical control of $\mathrm{U}(\mathrm{VI})$ bioavailability. Environ. Sci. Technol. 40 (12), 3986-3995.

Yahya, A., Hallberg, K.B., Johnson, D.B., 2008. Iron and carbon metabolism by a mineraloxidizing Alicyclobacillus-like bacterium. Arch. Microbiol. 189 (4), 305-312.

Yang, Y., Yang, L.I., Sun, Q.Y., 2014. Archaeal and bacterial communities in acid mine drainage from metal-rich abandoned tailing ponds, Tongling, China. Trans. Nonferrous Metals Soc. China 24 (10), 3332-3342.

Yazhikov, V., 1996. Uranium raw material base of the Republic of Kazakhstan and prospects of using in situ leach mining for its development. In Situ leach uranium Mining. Proceedings of IAEA Technical Committee Meeting, Almaty, Kazakhstan (September 1996). 